\title{
Improving Power Production in Linear Forms of Microbial Fuel Cells
}

\author{
Jerome T. Babauta, Y. Meriah Arias-Thode, Kristen \\ Fencil, Lewis Hsu, Gabriel Tukeman, and D. Bart \\ Chadwick \\ Environmental Sciences \\ Space and Naval Warfare Systems Center-Pacific \\ San Diego, United States \\ meriah.ariasthode@navy.mil
}

\begin{abstract}
Benthic microbial fuel cells (BMFCs) are devices that generate persistent energy by coupling bioanodes and biocathodes through an external energy harvester. Advances in BMFC system design have increased feasibility for its use in ocean monitoring. Previous iterations of BMFCs designed by this same group have relied upon carpet like anodes to harvest energy from electrochemically active bacteria in the sediment at power densities of $10-20 \mathrm{~mW} / \mathrm{m}^{-2}$. Although successful, these 2D anodes are difficult to deploy. In this paper, we evaluate linear cable anodes as an alternative scaling strategy. Commercially manufactured, these cable anodes are wound around insulated underwater cables and can be handled similar to linear hydrophone arrays. Used as delivered, cable anodes performed poorly and generated $\sim 0.3$ $\mathrm{mW} / \mathrm{m}$. To improve power production, we added a washing step to remove any chemical binders used in manufacturing and frayed the cable, exposing short strands of carbon yarn. Treated cable anodes generated 1-2 $\mathrm{mW} / \mathrm{m}$, which was comparable to and slightly improved over the performance of carpet like anodes.
\end{abstract}

Keywords-BMFC; MFC; SMFC;Energy harvester; Power source; San Diego Bay; Carbon cloth

\section{INTRODUCTION}

Microbial fuel cells (MFCs) are devices that generate electricity using bionanodes and/or biocathodes [1]. The electricity generated is not substantial; however, the current produced is continuous. This provides a steady source of electricity that can be harnessed. MFCs are reported in the literature for several purposes which are: 1) to demonstrate novel uses/applications of MFCs coupled to other technologies $[2,3] ; 2)$ to provide field-scale demonstrations and feasibility studies [4-6]; and 3) document new materials and methods to improve the performance of laboratory-scale MFCs [7]. Although the concept of the MFC is not new and was first mentioned in 1910 [8], advancements in MFC technology are needed to diversify opportunities for its application in renewable strategies. Examples include implementing battery-less sensors in the environment [9] and recovering waste energy [10]. In particular, this focus is on MFCs deployed in marine environments referred to as benthic (sediment) microbial fuel cells (BMFCs) [6].

The BMFCs in this article utilize electricallycoupled bioanodes and biocathodes to generate power for sensing applications [11]. Sensors monitor and report environmental parameters as well as human / animal activities in a marine environment. To effectively couple to sensors, BMFCs need to be minimally intrusive, yet provide adequate power to a sensor array. Thus, advancement in BMFC technology relies on implementing design strategies that scale in size, are durable at all scales, and can be deployed with minimal disturbance to its local surroundings. Inspiration for such a design was obtained from coastal monitoring using large, linear hydrophone arrays [Navy Program Management Systems 485]. Linear BMFCs are thus lengths of insulated underwater cable wrapped with carbon fiber bundles, an appropriate current collector, and secured by a web of the synthetic fiber, Dacron ${ }^{\circledR}$. The carbon cables act as the anode, are easy to handle on reels, and can transmit power along the underwater cable.

Typically, BMFCs are constructed of fabric panels or brush-type carbon electrodes because of their durability during deployment [11]. It was previously shown that BMFCs in the same sediments using carbon fabric panels generated power densities of approximately $10-20 \mathrm{~mW} / \mathrm{m}^{2}$ in an anode-limited setup [6]. The expected power density was experimentally verified for a 1:8 aspect ratio at surface areas $\sim 0.01 \mathrm{~m}^{2}$. For linear forms of BMFCs, length is the appropriate scale factor instead of surface area. On a linear basis at a 1:8 aspect ratio and a surface area of $0.01 \mathrm{~m}^{2}, \sim 20$ $\mathrm{mW} / \mathrm{m}^{2}$ becomes $\sim 0.7 \mathrm{~mW} / \mathrm{m}$. Thus, linear BMFCs should meet or exceed $\sim 0.7 \mathrm{~mW} / \mathrm{m}$ to be competitive with carbon fabric panels.

In this paper, we evaluated the power output of commercially-manufactured carbon cable anodes in an anode-limited BMFC setup. We further improved the power output of the commercial carbon cables by removing some of the synthetic binders used in the manufacturing process and introducing frayed fiber ends to the carbon cables that increased the footprint of anodes. We demonstrate the feasibility of linear forms of BMFCs that can be scaled in length while still remaining durable and easy to handle.

\section{MethodS}

\section{A. Carbon cable anode construction}

The cable used to make the anodes in this study was obtained from South Bay Cable Corp (SB-48923; Idyllwild, $\mathrm{CA}$ ) and is shown in Fig. 1. This cable consisted of an inner layer of carbon yarn covered by a titanium wire mesh, in turn covered by another layer of carbon yarn, which was held in 
place by a web of Dacron ${ }^{\circledR}$ filament. The carbon yarn had been coated with a binder mixture consisting of polyvinyl alcohol (PVA), food-grade starch, and EVANOL $\AA$, which is a proprietary fatty alcohol mixture [South Bay Cable, pers.comm.]. From here, this specific binder mixture will be referenced as, 'Binder' to distinguish from non-specific binders. The innermost layer of the cable was an insulated $\mathrm{Cu}$ wire bundle.

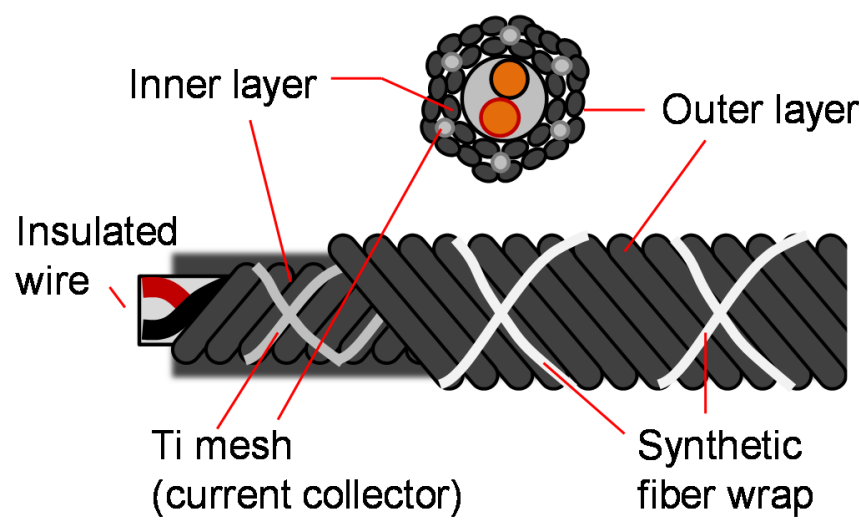

Fig. 1. Diagram indicating construction of the carbon cable. An insulated wire is wrapped with two layers of carbon yarn held together by a synthetic fiber wrap. Between the two layers of yarn is a Ti wire mesh that acts as the current collector. Connection to the anode is made through the Ti wire mesh. The insulated wire is a pair of braided $\mathrm{Cu}$ wires.

\section{B. Fraying}

The process of fraying the cable anodes involved exposing short strands of the carbon yarn as shown in Fig. 2A. To do this, mini scissors were used to cut two adjacent strands of carbon yarn taking care not to cut the Dacron ${ }^{\circledR}$ fibers. As depicted in Fig. 2A, the cut (red bars) was made preceding each crossover on the Dacron $\AA$ fibers. The exposed ends were then carefully pulled back in the direction of the arrow and under the Dacron ${ }^{\circledR}$ fiber. When all cuts were made, frays were approximately one inch long with one inch spacing along the cable anodes.
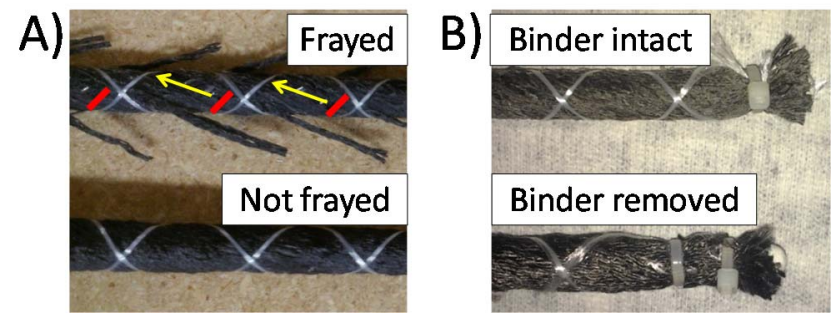

Fig. 2. Photos of anodes A) before and after fraying and B) before and after Binder removal.

\section{Binder removal}

Heating in water to $80-90^{\circ} \mathrm{C}$ was expected to be able to remove most of the PVA (and presumably, most if not all of the other binders) from the cable segments [12]. To seal off the wire bundle inside the cables, the outer carbon layer on each end was peeled back to better expose the wire bundle cut end. Then the wire bundles were sealed at the cut ends with Marine Adhesive Sealant Fast Cure 5200 (3M; St. Paul, $\mathrm{MN}$ ), taking care not to seal the carbon yarn to the wire bundle to prevent wicking of moisture into the wire bundle. Carbon yarn was secured in place at one end of each cable segment using tie-wraps after the sealant had dried overnight and then connecting wires attached on the other end.

Anodes were submerged with $\mathrm{diH} 2 \mathrm{O}$ and placed in a large container (ends covered in plastic and not submerged). Water was heated to approximately $60^{\circ} \mathrm{C}-95^{\circ} \mathrm{C}$; and that temperature range was maintained for 5 hours and then turned off. Anodes were left overnight in the water. The procedure was repeated two times; with a diH2O rinse post soaking. Anodes were then removed from the water and squeezed with paper towels to remove excess water. To dry completely they were all placed in a fume hood in an upright position. Upon completion it was observed that the carbon yarn on the treated cables was softer and more pliable than the untreated carbon anodes. The result was an anode surface visibly distinct from the untreated anode. Fig. 2B shows a more metallic luster on the anode after the Binder was removed. Furthermore, handling of the treated anode caused a mild skin irritation consistent with exposed carbon fiber.

\section{Titanium wire connection to anodes}

Connecting wire for the cable anodes was obtained from Fort Wayne Metals (Fort Wayne, IN), size 0.026/0.046 Black ETFE, type CPTI GR1, part no. FWMSPA012HRO3. The connecting wires for each of the cable anodes were cut to approximately $140 \mathrm{~cm}$ lengths and the insulation was stripped from a $3 \mathrm{~cm}$ length at one end of each segment. To attach the wires, the stripped end of each connector was inserted underneath the Ti wire mesh, making contact with several (2-3) of the individual wires in the mesh of each of the cable segments. Several tie-wraps were used to hold the connecting wire and carbon layer firmly in place.

\section{E. BMFC design and operation}

Sediment preparation: One tank was prepared for testing the anodes as part of a BMFC. Sediment for the BMFC was sourced from San Diego Bay, Marine Corp Recruit Depot $\left(32^{\circ} 44^{\prime} 20.65^{\prime} \mathrm{N}, 177^{\circ} 12^{\prime} 31.42^{\prime \prime} \mathrm{W}\right)$ and was used to make a layer about $25 \mathrm{~cm}$ deep. The tank was supplied with fresh flowing seawater and air bubbled with two aquarium pumps for 2 bubblers. Sediment was allowed to settle two days until the water cleared before anodes were buried approximately $10 \mathrm{~cm}$ and leaving at least $10 \mathrm{~cm}$ from the sides of the tank and each other. All anode connections were attached to a terminal block and connected to a single carbon cloth cathode (Twice the surface area of all connected anodes) suspended in the water column. Four days after the anodes were buried in sediment, the cathode wire was connected to complete the circuit, to begin the test period. The open circuit potential was approximately $0.7-0.8 \mathrm{~V}$. For the test period, the voltage was regulated using in-house developed printed circuit boards (PCBs) to maintain the voltage to $0.4 \mathrm{~V}$. These PCB's and the Madgetech data loggers were kept in a water-tight box. Resistors were all set at $1000 \Omega$ to start experiment and were changed periodically to keep output signal $\mathrm{V}$ between $0.03-0.1 \mathrm{~V}$ due to equipment limitations (circuit boards and Madgetech 8 channel data loggers). In general, the potentiostat boards are designed to hold a system at a working potential equivalent to a reference set point; Ag/AgCL reference (Accumet \#13- 
620-273) designated before operation by tuning an onboard potentiometer.

\section{F. Capacitance measurements}

Capacitance of cable anodes were tested using a Gamry Interface 1000 potentiostat (Gamry Instruments, Warminster PA). The cable anode, a counter electrode made of carbon fabric cloth (Panex 30 PW-06; Zoltek Companies Inc, St Louis, $\mathrm{MO}$ ), and a $\mathrm{Ag} / \mathrm{AgCl}$ reference electrode was placed into a glass tray filled with seawater. Once in place, cyclic voltammograms were obtained to estimate capacitance following:

$$
\Delta i=2 C v
$$

Where $\Delta i$ is the difference between the forward and reverse current (A) at $0.22 \mathrm{~V}_{\mathrm{Ag} / \mathrm{AgCl}}, C$ is the effective capacitance $(\mathrm{F})$, and $v$ is the scan rate $(\mathrm{V} / \mathrm{s})$. The factor of two accounts for the charge and discharge of the forward and reverse scans. The following parameters were used: initial potential $0.3 \mathrm{~V}_{\mathrm{Ag} / \mathrm{AgCl}}$, final potential $0.1 \mathrm{mV}_{\mathrm{Ag} / \mathrm{AgCl}}$, step size $1 \mathrm{mV}$. The second scan was used to avoid the initial charging of the anode. $\Delta i$ was estimated at scan rates of 10,50 , and 100 $\mathrm{mV} / \mathrm{s}$. A plot of $\Delta i$ vs. $v$ was made and $C$ estimated from the slope following (1).

\section{RESULTS}

\section{A. Effect of Binder removal on power generation}

Power generation of two types of cable anodes were tested in duplicate for over 25 days in an anode-limited BMFC. A pair of cable anodes used as-is (untreated) with the Binder intact and another pair of cable anodes that were treated in the heated bath. Binder removal resulted in a mass loss of $1.49 \pm 0.02 \mathrm{~g}(\mathrm{n}=3)$, which was $8.3 \%$ of the original mass. Fig. 3 shows two distinct power performances between the untreated and treated anodes. Untreated anodes showed a two-peak power response at day 6 and day 9 followed by a consistently poor power density output of $0.18 \mathrm{~mW} / \mathrm{m}$ at the end of 26 days of operation. The treated anodes responded in the typical growth response for BMFCs reaching a power density of 1.57 and $1.94 \mathrm{~mW} / \mathrm{m}$. At peak, untreated anodes performed at only $54 \%$ of the average steady power of the treated anodes. At steady performance, that percentage drops to only $11 \%$, which proves that the Binder had an overall negative effect on anode performance.

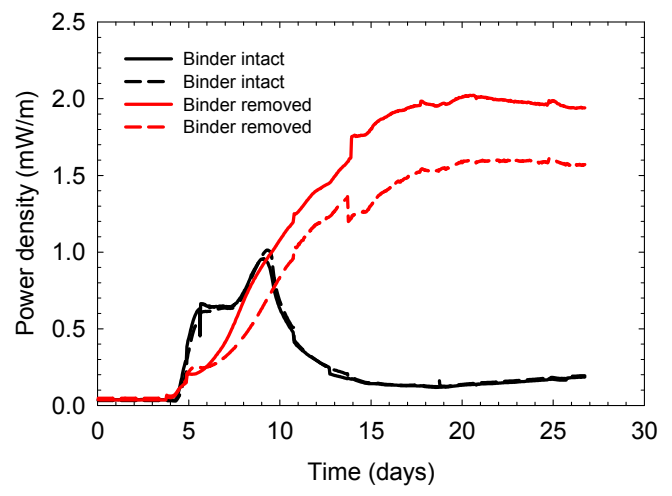

Fig. 3. Power generation of BMFCs over time of cable anodes with and without Binders. Anodes were not frayed. The presence of the Binders reduced power density by $9.5 \times$.

\section{B. Effect of fraying on power generation}

In a separate experiment, the effect of fraying was tested on anode-limited BMFCs. Similar to the Binder removal experiment, two sets of duplicate cable anodes were prepared with one set frayed and the second set not frayed. Fig. 4 shows that frayed cable anodes reached power densities of 1.48 and $1.33 \mathrm{~mW} / \mathrm{m}$ after 47 days of BMFC operation. On average, fraying produced $8.3 \times$ more power over the unfrayed cable anodes, which produced 0.21 and $0.13 \mathrm{~mW} / \mathrm{m}$ after 47 days of BMFC operation. The arrow in Fig. 4 points out the same peak behavior observed in the Binder removal experiment shown in Fig. 3. However, the peak height reached only approximately $0.2-0.3 \mathrm{~mW} / \mathrm{m}$ as compared to $\sim 1 \mathrm{~mW} / \mathrm{m}$ in Fig. 3. We also note that the end of experiment power output for both controls in Fig. 3 and Fig. 4 were consistent, which was expected because all four anodes were used untreated. The difference in peak heights cannot be accounted for based on Fig. 3 and Fig. 4 alone.

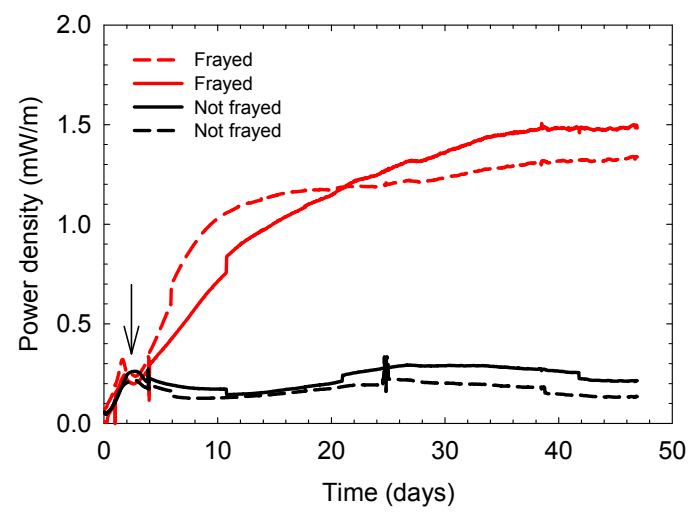

Fig. 4. Power generation of BMFCs over time of cable anodes with and without fraying. Binder was left intact for all anodes.

\section{Cumulative effect of Binder removal and fraying}

To isolate the discrepancy in Fig. 3 and Fig. 4, we ran a $2 \times$ combinatorial experiment under the same conditions. The power generation of the eight BMFCs operated over 42 days is shown in Fig. 5. First, indicated by the arrow in Fig. 5, all four cable anodes showed nearly identical peaks consistent with the Binder left intact. With peak heights of approximately $0.25 \mathrm{~mW} / \mathrm{m}$, the data are consistent with Fig. 4 and not Fig. 3. One critical conclusion from Fig. 5 is that Binder removal sped up the onset of power generation. This was true regardless of the fraying treatment. In this particular experiment, exponential power generation was observed one week earlier. The fraying treatment in Fig. 5 improved the steady power output by $0.4 \mathrm{~mW} / \mathrm{m}$ with the Binder intact and 0.7 with the Binder removed. Noting that Fig. 4 shows an improvement of $1.2-1.3 \mathrm{~mW} / \mathrm{m}$ caused by fraying, we recognized that there was no consistent change in magnitude. However, fraying always had a positive effect on power generation. 


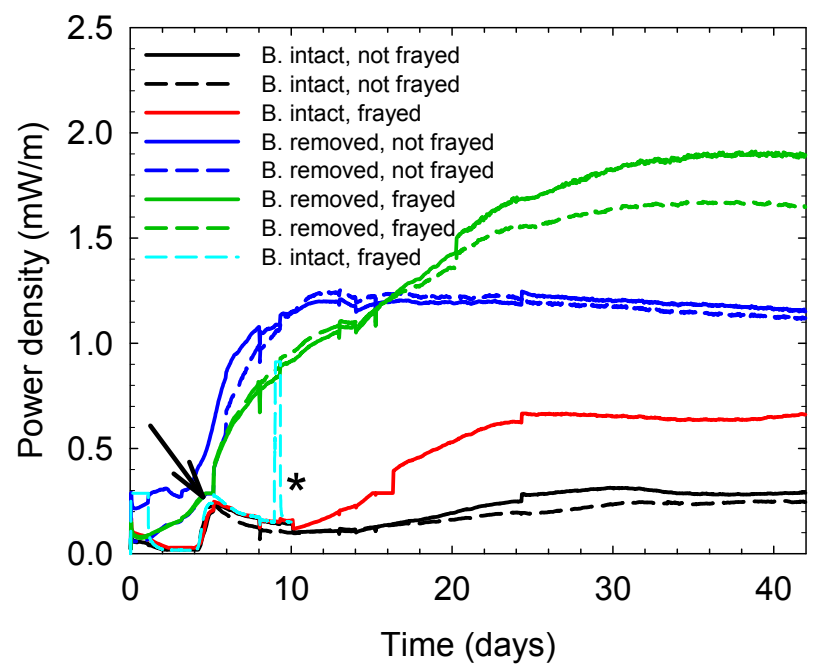

Fig. 5. Power generation of BMFCs combining the Binder removal and fraying treatments at various treatment levels. Binder abbreviated to "B." for clarity. Asterick refers to an electronics malfunction that crippled that particular BMFC. Data prior to malfunction was still valid and is thus presented.

\section{Effective surface area of cable anodes}

In addition to testing the Binder removal and fraying cumulatively, we also tested for changes in cable anode surface area during treatment. We used electrochemical capacitance measurements to estimate changes in the effective surface area of the cable anodes. While not a direct measure of the true surface area, comparisons between specific capacitance allow for detection of large surface area changes. Table I shows that when either treatment was applied, changes to specific capacitance were inconclusive. This indicated that no significant changes in effective surface area were measured with each treatment. For consistency, we also measured the specific capacitance of untreated cable anodes with the outer layer (see Fig. 1) removed and confirmed a $\sim 50 \%$ decrease. Given that the volume of the outer layer should be slightly larger than the inner layer, $50 \%$ is less than expected. In terms of total volume, the outer layer accounts for $58 \%$ neglecting the $\mathrm{Ti}$ mesh. A simple explanation for the difference is a higher surface area to volume ratio in the inner layer.

TABLE I. SPECIFIC CAPACITANCE OF THE CABLE ANODES WITH EACH TREATMENT. FOR CONSISTENCY, SPECIFIC CAPACITANCE OF THE CABLE ANODE WITH THE OUTER LAYER REMOVED IS SHOWN.

\begin{tabular}{|c|c|}
\hline Treatment & Specific capacitance (F/m) \\
\hline No fray, with Binder & $0.49 \pm 0.04$ \\
\hline Fray, with Binder & $0.45 \pm 0.06$ \\
\hline No fray, without Binder & $0.48 \pm 0.01$ \\
\hline $\begin{array}{c}\text { Outer layer removed } \\
\text { (No fray, with Binder) }\end{array}$ & $0.25 \pm 0.01$ \\
\hline
\end{tabular}

\section{DISCUSSION}

Both Binder removal and fraying have a net positive effect on power generation by BMFCs studied here. We tabulated the final power densities at the end of each experiment and calculated means and standard deviations for each treatment, which is shown in Table II. Used as-is, the cable anodes perform poorly against our benchmark of $\sim 0.7$ $\mathrm{mW} / \mathrm{m}$. Operating at $30 \%$ of the benchmark is not acceptable. Factoring in either treatment, however, improves the cable anode performance and makes it competitive with the carbon fabric panels. Within the context of the comparison between fabric panel anodes and cable anodes, there is merit in considering the linear form as it bypasses most of the deployment issue related to fabric panel anodes [11].

TABLE II. MEAN POWER DENSITY OF EACH ANODE MODIFICATION TAKEN FROM FIG. 3 THROUGH FIG. 5.

\begin{tabular}{|c|c|}
\hline Treatment & $\begin{array}{c}\text { Mean power density and std. dev. } \\
(\mathbf{m W} / \mathbf{m})\end{array}$ \\
\hline Binder intact, no fraying & $0.21 \pm 0.06(\mathrm{n}=6)$ \\
\hline Binder intact, fraying & $1.16 \pm 0.44(\mathrm{n}=3)$ \\
\hline Binder removed, no fraying & $1.45 \pm 0.39(\mathrm{n}=4)$ \\
\hline Binder removed, fraying & $1.77 \pm 0.17(\mathrm{n}=2)$ \\
\hline
\end{tabular}

The standard deviations in Table II indicate a confounding factor not accounted for in the BMFC tests. Because the cumulative test in Fig. 5 was internally consistent, the confounding factor likely changed between each experimental run. Furthermore, the fact that the untreated cable anodes performed within such a narrow window across all three experimental runs suggests that the factor is related to the current magnitude. BMFC geometry, sediment quality, seawater quality, and inclement weather all affect current magnitude and subsequently run to run variability in our system.

One factor that was accounted for was the changes to effective surface area, estimated by specific capacitance. Because the specific capacitance changed minimally between treatments, we concluded that fraying the cable anodes likely enhanced the availability of surface area by exposing the inner layer directly to sediment and subsequently increasing flux rates. The fact that a simple geometric change caused a modest increase in power density shows that not all of the electrode was used effectively. Thus, one practical solution to this limitation is to fray cable-type anodes. The improved power density by removing the binder is difficult to account for without an analysis of the microbial community on the electrode surfaces and the adjacent sediment. Food-grade starch is a well-known potential food source for anodic microbial communities [12]. PVA is biodegradable by Pseudomonas spp. [13]. However, PVA is used as a membrane separator for MFCs [14] and is a known antifouling agent [15]. Evanol ${ }^{\circledR}$, a proprietary blend containing the dimeric surfactant polyoxyethylene (20) cetyl ether and fatty alcohols, exhibits antibacterial activity [16]. Thus, the Binder could both promote and suppress power 
generation at the anode, which may account for the initial boost in BMFC power density with the Binder left intact.

\section{CONCLUSiOnS}

By combining both the Binder removal procedure and fraying, we observed a six-fold increase in power density of similarly-constructed BMFCs operating side-by-side. The cumulative effect of each treatment was additive. Binder removal affected both the short-term and long-term BMFC performance whereas fraying only affected the long-term performance. Treated cable anodes generated $1-2 \mathrm{~mW} / \mathrm{m}$, which was comparable to and slightly improved over the performance of carpet like anodes. In order to make the highest-performing linear BMFCs, it recommended that both fraying and Binder removal treatments be applied.

\section{ACKNOWLEDGMENT}

This effort was funded by ONR grant \# N0001416WX00789 and by the Naval Innovative Science and Engineering 219 funds. The authors wish to thank Matthew Bond who supported the setup and monitoring of the experiment and Bradley Davidson for supporting the field collection of sediments.

\section{REFERENCES}

[1] Logan, B. E.; Hamelers, B.; Rozendal, R.; Schröder, U.; Keller, J.; Freguia, S.; Aelterman, P.; Verstraete, W.; Rabaey, K., Microbial Fuel Cells: Methodology and Technology. Environmental Science \& Technology 2006, 40, (17), 5181-5192.

[2] Weld, R. J.; Singh, R., Functional stability of a hybrid anaerobic digester/microbial fuel cell system treating municipal wastewater. Bioresource Technology 2011, 102, (2), 842-847.

[3] Ewing, T.; Babauta, J. T.; Atci, E.; Tang, N.; Orellana, J.; Heo, D.; Beyenal, H., Self-powered wastewater treatment for the enhanced operation of a facultative lagoon. Journal of Power Sources 2014, $269,284-292$

[4] Zhang, F.; Ge, Z.; Grimaud, J.; Hurst, J.; He, Z., Long-Term Performance of Liter-Scale Microbial Fuel Cells Treating Primary Effluent Installed in a Municipal Wastewater Treatment Facility. Environmental Science \& Technology 2013, 47, (9), 4941-4948.

[5] Ghadge, A. N.; Jadhav, D. A.; Ghangrekar, M. M., Wastewater treatment in pilot-scale microbial fuel cell using multielectrode assembly with ceramic separator suitable for field applications. Environmental Progress \& Sustainable Energy 2016, n/a-n/a.

[6] Hsu, L.; Chadwick, B.; Kagan, J.; Thacher, R.; Wotawa-Bergen, A.; Richter, K., Scale up considerations for sediment microbial fuel cells. RSC Advances 2013, 3, (36), 15947-15954.

[7] Choi, S., Microscale microbial fuel cells: Advances and challenges. Biosensors and Bioelectronics 2015, 69, 8-25.

[8] Bennetto, P. H., Microbial Fuel Cells. Life Chemistry Reports 1984, 2, 363-453.

[9] Wang, H.; Park, J.-D.; Ren, Z. J., Practical Energy Harvesting for Microbial Fuel Cells: A Review. Environmental Science \& Technology 2015, 49, (6), 3267-3277.

[10] Chouler, J.; Padgett, G. A.; Cameron, P. J.; Preuss, K.; Titirici, M.M.; Ieropoulos, I.; Di Lorenzo, M., Towards effective small scale microbial fuel cells for energy generation from urine. Electrochimica Acta 2016, 192, 89-98.

[11] Arias-Thode, Y. M.; Hsu, L.; Kagan, J. A.; Chadwick, D. B. In Longterm performance of segmented benthic microbial fuel cells, OCEANS 2015 - Genova, 18-21 May 2015, 2015; 2015; pp 1-5.

[12] Pant, D.; Van Bogaert, G.; Diels, L.; Vanbroekhoven, K., A review of the substrates used in microbial fuel cells (MFCs) for sustainable energy production. Bioresource Technology 2010, 101, (6), 15331543.
[13] Shimao, M.; Saimoto, H.; Kato, N.; Sakazawa, C., Properties and roles of bacterial symbionts of polyvinyl alcohol-utilizing mixed cultures. Applied and Environmental Microbiology 1983, 46, (3), 605-610.

[14] Chen, G.; Zhang, F.; Logan, B. E.; Hickner, M. A., Poly(vinyl alcohol) separators improve the coulombic efficiency of activated carbon cathodes in microbial fuel cells. Electrochemistry Communications 2013, 34, 150-152.

[15] Krishnan, S.; Weinman, C. J.; Ober, C. K., Advances in polymers for anti-biofouling surfaces. Journal of Materials Chemistry 2008, 18, (29), 3405-3413.

[16] Sheikh, M. S.; Khanam, A. J.; Matto, R.-u. H.; Kabir-ud-Din, Comparative Study of the Micellar and Antimicrobial Activity of Gemini-Conventional Surfactants in Pure and Mixed Micelles. Journal of Surfactants and Detergents 2013, 16, (4), 503-508. 